\title{
CÁC TIÊU ĐỀ BẢN TIN CỦA THỜI BÁO THE NEWYORK TIMES VỀ CUỘC XUNG ĐỘT Ở' DẢI GAZA NĂM 2014
}

\author{
Trịnh Hồng Nam* \\ Khoa Sau đại học, Trưòng Đại học Ngoại ngũu, ĐHQGHN, \\ Phạm Văn Đồng, Cầu Giáy, Hà Nội, Việt Nam \\ Nhận bài ngày 20 tháng 04 năm 2018 \\ Chỉnh sửa ngày 21 tháng 05 năm 2018; Chấp nhận đăng ngày 22 tháng 05 năm 2018
}

Tóm tắt: Ngôn ngữ có vai trò quan trọng trong việc truyền tải tư tưởng của người viết về một vấn đề nào đó tới độc giả, để truyền tải thông tin chính xác đòi hỏi khả năng diễn đạt ngôn ngữ của người viết ở các mức độ, chức năng ngôn ngữ khác nhau. Bài viết nghiên cứu khảo sát 50 tiêu đề bản tin về mặt đặc điểm, cấu trúc ngôn ngữ và phương tiện, biện pháp tu từ được các nhà báo của thời báo The New York Times sử dụng để đưa tin về cuộc xung đột ở dải Gaza năm 2014. Kết quả cho thấy người viết có xu hướng viết hoa chữ cái đầu của các từ mang thông tin, giản lược mạo từ, trợ động từ trong các tiêu đề bản tin, người viết sử dụng nhiều các cấu trúc cú có vị từ biến ngôi cũng như sử dụng các phương tiện tu từ: ẩn dụ, hoán dụ và biện pháp tu từ: câu hỏi tu từ và sóng đôi để kiến tạo các tiêu đề bản tin về cuộc xung đột nhằm thu hút sự chú ý của độc giả, đồng thời giúp tòa báo cập nhật các tiêu đề bản tin lên các trình duyệt và các trang mạng xã hội như facebook, twitter dễ dàng hơn, độc giả tiếp cận nội dung thông tin bài báo nhanh chóng, chính xác hơn. Qua bài viết, tác giả hy vọng đóng góp một phần nhỏ vào thực tiễn công tác giảng dạy đồng thời giúp cho người học sử dụng tốt cấu trúc, phương tiện và biện pháp tu từ trong việc thực hành viết các tiêu đề bản tin ở các chủ đề khác nhau, dịch tiêu đề bản tin cũng như nhận biết các dạng tiêu đề bản tin khi tiếp cận báo chí tiếng Anh ngoài đời thực.

Tù̀ khóa: cấu trúc, tiêu đề bản tin, phương tiện tu từ, xung đột, Israel, Palestine, Gaza

\section{Giới thiệu chung}

Xung đột ở dải Gaza nói riêng và xung đột giữa Israel và Palestine nói chung luôn là một trong những vấn đề nóng của tình hình thời sự thế giới và là tâm điểm đưa tin của các tòa báo quốc tế trong suốt 70 năm lịch sử thế giới hiện đại kể từ ngày nhà nước Israel ra đời (năm 1948). Cuộc xung đột kéo dài 50 ngày ở dải Gaza năm 2014 giữa Israel và Palestine (đại diện là chính quyền Hamas ở dải Gaza) được xem như là cuộc xung đột nguy hiểm nhất kể từ khi Israel kiểm soát dải Gaza năm 1967 và rút

*ĐT.: 84-916057398

Email: namthvnu@gmail.com quân năm 2005 với hơn 2131 người Palestine (70\% là dân thường bao gồm 1473 người lớn, 501 trẻ em) và 71 người Israel bị thiệt mạng (dẫn theo báo cáo thường niên về bảo vệ dân thường năm 2015 của Liên Hiệp Quốc).

Bài viết này tập trung nghiên cứu các đặc điểm ngôn ngữ và phân loại cấu trúc tiêu đề bản tin cũng như các phương tiện và biện pháp tu từ được các nhà báo/ban biên tập (gọi tắt là người viết) của thời báo The New York Times (The NYT) sử dụng trong việc kiến tạo các tiêu đề bản tin nhằm truyền tải thông tin, tư tưởng của mình về cuộc xung đột ở dải Gaza năm 2014 tới độc giả trên toàn thế giới nhanh nhất và hiệu quả nhất. Bằng việc khảo sát, phân loại các đặc điểm, cấu 
trúc tiêu đề bản tin và phân tích các phương tiện, biện pháp tu từ được sử dụng trong các tiêu đề bản tin về cuộc xung đột ở dải Gaza năm 2014, tác giả muốn đóng góp một phần hiểu biết nhằm giúp giảng viên, người học lĩnh hội tốt hơn về ngôn ngữ báo chí tiếng Anh cũng như dạy và học tốt học phần tiếng Anh chuyên ngành (ESP).

\section{Cơ sở lý luận và tổng quan tình hình nghiên cứu}

\section{1. Đưòng hướng tiếp cận nghiên cưu bản tin}

Cuộc cách mạng công nghiệp 4.0 đã và đang tác động mạnh mẽ đến mọi lĩnh vực của cuộc sống dẫn đến yêu cầu báo chí truyền thông cũng phải thay đổi để thích ứng, phát triển và chứng tỏ được thế mạnh, vị trí, tầm quan trọng của mình đối với đời sống xã hội. Trong thực tế, độc giả tiếp cận các sản phẩm của báo chí nói chung và các bản tin nói riêng với nhiều mục đích khác nhau như cập nhật thông tin, giải trí, người viết thì cố gắng viết những bản tin hoàn hảo, trung thực nhất. Nghiên cứu bản tin được Bednarek và Caple (2012: 7-13) đề cập với hai đường hướng nghiên cứu chính: đó là đường hướng nghiên cứu bản tin từ bình diện ngôn ngữ học và từ bình diện báo chí và truyền thông. Từ bình diện ngôn ngữ học, Bednarek và Caple (2012: 7-10) đề cập đến tám đường hướng nghiên cứu bản tin như đường hướng nghiên cứu xã hội học (The sociolinguistic approach), đường hướng nghiên cứu phân tích hội thoại (The conversation analytical approach), đường hướng nghiên cứu ngôn ngữ học chức năng hệ thống (The systemic functional linguistic approach), đường hướng nghiên cứu dụng học/phong cách học (The pragmatic/stylistic approach), đường hướng nghiên cứu chú trọng thực tiễn (The practice-focused approach), đường hướng nghiên cứu ngôn ngữ học khối liệu (The corpus linguistic approach), đường hướng nghiên cứu lịch đại (The diachronic approach), và đường hướng nghiên cứu phê phán (The critical approach). Từ bình diện báo chí và truyền thông, Bednarek và Caple (2012:
11-13) đề cập bốn hướng nghiên cứu như nghiên cứu lý thuyết về sự tác động (Response (audience) theory), nghiên cứu lý thuyết sản phẩm đầu ra (Output (institutions) theory), nghiên cứu lý thuyết phương tiện truyền tải (Medium (technology) theory), và nghiên cứu lý thuyết về nội dung (Content (texts) theory).

Trong bài viết này, tác giả nghiên cứu tiêu đề bản tin xét theo đường hướng nghiên cứu ngôn ngữ học chức năng hệ thống (systemic functional linguistics) trong đó hệ thống ngôn ngữ được hình thành từ chức năng mà nó biểu đạt. Ngôn ngữ học chức năng hệ thống nghiên cứu mối quan hệ giữa ngôn ngữ và các chức năng của nó trong bối cảnh xã hội cụ thể. Ngôn ngữ, là nguồn tạo nghĩa (language is a meaningmaking resource), có ba chức năng cơ bản mà theo Halliday $(1978,1994)$ đó là ba siêu chức năng: chức năng tư tưởng/tạo ý (ideational) tức con người sử dụng ngôn ngữ để miêu tả thế giới khách quan, phản ánh kinh nghiệm (experiential) của con người; chức năng giao tiếp liên nhân (interpersonal) hay con người sử dụng ngôn ngữ để mã hóa vai trò và địa vị xã hội của những người tham gia giao tiếp như người nói/người nghe hoặc người viết/người đọc, hoặc cho phép con người trong cùng một cộng đồng giao tiếp, tương tác với nhau; và chức năng tạo văn bản/ ngôn bản (textual) hay sự biến đổi trong cách sử dụng ngôn ngữ tùy theo kênh giao tiếp để hiện thực hóa chức năng tư tưởng và chức năng tương tác liên nhân. Cả ba siêu chức năng trên của ngôn ngữ được thể hiện trong ngôn cảnh cụ thể với ba thành phần bao gồm: trường (field) hay phạm vi, chủ đề, bối cảnh, mục đích của sự tương tác; bầu không khí (tenor) hay quan hệ giữa những nhân vật tham gia tương tác/giao tiếp; và thức/phương tiện/thức giao tiếp (mode).

Một nghiên cứu khảo sát tổng thể cần xem xét đầy đủ cả ba siêu chức năng này thể hiện như thế nào trong một văn bản/ngôn bản. Trong phạm vi của bài viết này, tác giả tập trung vào việc người viết sử dụng nguồn lực ngôn ngữ như đặc điểm ngôn ngữ, cấu trúc 
ngôn ngữ, phương tiện ngôn ngữ để truyền tải tư tưởng của mình thông qua việc kiến tạo văn bản (trong trường hợp này, sản phẩm văn bản là tiêu đề bản tin) tới độc giả.

\subsection{Tiêu đề}

\subsection{1. Định nghĩa tiêu đề}

Tiêu đề bản tin (news headline/title) được đề cập trong bài viết là một thể loại độc nhất của tiêu đề báo chí với số lượng câu chữ ít, ngắn gọn nhưng chứa đựng nhiều thông tin. Tiêu đề thường có kích cỡ chữ lớn, đậm, dễ nhìn nằm ở vị trí trên cùng của một bài báo nhằm thu hút sự chú ý của độc giả (Reah, 2002: 13; Cotter, 2010: 26). Tiêu đề là một thành phần quan trọng trong cấu trúc của một bài báo, nó quyết định đến sự thành công trong việc thuyết phục độc giả theo dõi thông tin chi tiết trong các phần tiếp theo của bài báo.

Khung lý thuyết phân tích cấu trúc một bản tin (news schemata) như van Dijk (1985) gọi đó là "tổ chức thông tin tổng thể" (global news organization) bao gồm các chủ đề (tức cấu trúc ngữ nghĩa) và sơ đồ siêu cấu trúc (tức cấu trúc trật tự thông tin). Tổ chức thông tin tổng thể được thể hiện ở các tiêu đề hoặc các đoạn dẫn nhập, chúng được sắp xếp thành các chủ đề có liên quan tới việc tổ chức trật tự thông tin của một bài báo. Cấu trúc trật tự thông tin thường bao gồm các phần: tóm tắt (tiêu đề và dẫn nhập), sự kiện chính, thông tin nền, kết quả, bình luận. Phần tóm tắt và sự kiện chính là bắt buộc, các tiểu loại tin khác nhau có cấu trúc trật tự thông tin khác nhau. Cấu trúc thông tin của một bản tin thường được tổ chức theo quan hệ thứ bậc với mức độ quan trọng nhất của thông tin xuất hiện trước và những thông tin ít quan trọng hơn xuất hiện sau trong bài viết (van Dijk, 1985).

\subsubsection{Vai trò của tiêu đề}

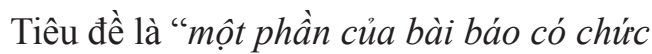
năng thu hút độc giả" (Bell, 1991: 189), vì vậy vai trò quan trọng nhất của tiêu đề là lôi kéo sự chú ý của độc giả và dẫn dắt độc giả tiếp tục quan tâm đến phần nội dung của bài báo. Richardson (2007: 197) cho rằng tiêu đề thực thi hai chức năng chính là: chức năng ngữ nghĩa đối với văn bản tham chiếu và chức năng ngữ dụng đối với độc giả của văn bản đang được đề cập. Các tiêu đề thường có bốn chức năng chính là: (1) tóm tắt thông tin, (2) đánh giá tầm quan trọng của câu chuyện, (3) hé lộ các chi tiết của câu chuyện và (4) thuyết phục người chỉ nhìn lướt qua trở thành người đọc nội dung (Harkrider, 1997).

\subsection{3. Đặc điểm ngôn ngũ của tiêu đề}

Tiêu đề được xem như một thông điệp đầu tiên của bài báo mà người viết muốn gửi tới độc giả, do đó để có một tiêu đề hay, hiệu quả đòi hỏi nhiều vào ý tưởng của người viết về mặt cấu trúc và nội dung. Các đặc điểm ngôn ngữ của tiêu đề được Nguyễn Thị Thanh Hương (2017: 50) trích từ Mallette (1990) và Harkrider (1997) như sau:

Bảng 1. Các đặc điểm ngôn ngữ của tiêu đề (Nguyễn Thị Thanh Hương, 2017: 50)

\begin{tabular}{|c|c|}
\hline TT & Đặc điểm ngôn ngữ tiêu đề \\
\hline 1 & Nêu tình huống, chủ đề \\
\hline 2 & $\begin{array}{c}\text { Giới hạn về số lượng từ (không quá } 45 \text { ký } \\
\text { tự) }\end{array}$ \\
\hline 3 & $\begin{array}{l}\text { Câu có cấu trúc đơn giản nhưng ở dạng } \\
\text { đầy đủ (S-V) }\end{array}$ \\
\hline 4 & $\begin{array}{c}\text { Cho phép giản lược mạo từ, trợ động từ "to } \\
\text { be" và giới từ }\end{array}$ \\
\hline 5 & Dùng dạng phân từ quá khứ thay cho bị động \\
\hline 6 & $\begin{array}{l}\text { Dùng dạng hiện tại đơn thay cho tiếp diễn } \\
\text { và hoàn thành }\end{array}$ \\
\hline 7 & $\begin{array}{c}\text { Dạng nguyên thể "to-V" thể hiện nghĩa } \\
\text { tương lai }\end{array}$ \\
\hline 8 & Dùng câu hạt nhân (S-V-O) \\
\hline 9 & Chuỗi các danh từ \\
\hline 10 & $\begin{array}{c}\text { Dùng dấu ':' phân cách chủ ngữ và phần } \\
\text { còn lại của tiêu đề }\end{array}$ \\
\hline 11 & Từ ngắn có khả năng biểu cảm \\
\hline
\end{tabular}


Bảng đặc điểm ngôn ngữ tiêu đề trên sẽ được dùng để so sánh khi mô tả và phân loại tiêu đề bản tin trong phần phân tích số liệu của bài báo.

\subsubsection{Phân loại tiêu đề bản tin}

Tiêu đề bản tin được Bonyadi và Samuel (2011: 3) phân loại thành hai cấu trúc chính là cấu trúc tiêu đề vị từ (verbal headlines) và cấu trúc tiêu đề phi vị từ (nonverbal headline), trong đó: cấu trúc tiêu đề vị từ là những tiêu đề có một cú chứa vị từ (verbal clause) được Bonyadi và Samuel (2011) phân chia thành ba loại cú chứa vị từ dựa theo sự phân loại cú của Quirk và các cộng sự (1985: 992): cú có vị từ biến ngôi (finite clause), cú có vị từ không biến ngôi (nonfinite clause) và tiểu cú không có vị từ (verbless clause). Động từ trong cú có vị từ biến ngôi thường được chia theo thì của động từ:

(Vd.1): Egypt Presents Proposal to Israel and Hamas for a Cease-Fire in Air Attacks. (Ai Cập đưa ra đề xuất ngừng bắn không chiến giữa Israel và Hamas) ${ }^{1}$

Động từ trong cú có vị từ không biến ngôi thường ở dạng nguyên thể và không chia theo thì và thường ở dạng nguyên thể có hoặc không "to" trước động từ, hoặc ở dạng “-ed" hoặc dạng “-ing”:

(Vd.2): Peering into Darkness Beneath the Israel-Gaza Border (Binh lính Israel săn lùng và phá hủy các đường hầm trong cảnh tối tăm ở biên giới Israel và Gaza)

Tiểu cú không có vị từ được xếp vào nhóm tiêu đề phi vị từ:

(Vd.3): For Gazans, an Anxious and Somber Ramadan (Tháng nhịn ăn Ramadan đầy âu lo và sợ hãi đối với người dân Gaza)

Cấu trúc tiêu đề phi vị từ là những cấu trúc có chứa một danh từ hoặc một cụm danh tính.

\footnotetext{
${ }^{1}$ Những ví dụ trong bài này được chúng tôi tạm dịch theo nghĩa đen và diễn giải ý nghĩa của chúng trong bài báo được trích chứ chưa phải là phương án dịch tối ưu.
}

Dạng cấu trúc tiêu đề phi vị từ này thường có các thành phần bổ ngữ cho danh từ chính có chức năng "bổ sung thêm thông tin và đồng thời khu biệt tham chiếu cho danh tù"' (Quirk và cộng sự, 1985: 65). Cấu trúc tiêu đề phi vị từ được phân loại thành bốn dạng: Tiền phụ ngữ (Pre-modified), Hậu phụ ngũ̃ (Post-modified), Tiền và hậu phụ ngữ (Pre- and Post-modified), Phi phụ ngữ (Nonmodified) cho danh từ.

Trong bài viết này, cấu trúc tiêu đề bản tin được phân loại dựa trên sự phân loại của Bonyadi và Samuel (2011) về cấu trúc chính bao gồm cấu trúc tiêu đề vị từ, cấu trúc tiêu đề phi vị từ kết hợp với sự phân chia của Quirk và các cộng sự (1985) các cấu trúc chính này thành các tiểu mục khác nhau.

\subsection{Phưong tiện tu tù và biện pháp tu tù}

\subsection{1. Định nghĩa và chưc năng của phwơng tiện tu tù̀ và biện pháp tu tù̀}

Trong hoạt động giao tiếp, xuất phát từ mục đích giao tiếp cùng với phương tiện ngôn ngữ (ngôn ngữ trung hòa hoặc ngôn ngữ tu từ) sẵn có người sử dụng ngôn ngữ có thể lựa chọn những biện pháp sử dụng các phương tiện ngôn ngữ (theo cách thông thường hoặc theo cách đặc biệt như biện pháp tu từ) nhằm đạt tới hiệu quả diễn đạt hay, đẹp, hấp dẫn.

Phương tiện tu từ (PTTT) là "những phương tiện ngôn ngữ mà ngoài ý nghĩa cơ bản (ý nghĩa sự vật - logic) ra chúng còn có ý nghĩa bổ sung, còn có màu sắc tu từ. Những phương tiện tu từ từ vựng, ngữ nghĩa, cú pháp đều khác biệt đối lập tư từ học với những phương tiện trung hòa từ từ vựng, ngữ nghĩa, cú pháp" (Đinh Trọng Lạc, 1994: 43-44). Phương tiện tu từ là "công cụ giao tiếp hiệu quả nhất vì nhờ vào phương tiện tu từ chúng ta mới có thể truyền đạt ý tưởng một cách ấn tượng nhất” (Trần Huy Khánh, 2010: 127). Phương tiện tu từ là sự cường điệu hóa có chủ đích các đặc trưng về cấu trúc hay ngữ nghĩa của một đơn vị ngôn ngữ (Galperin, 1981). 
Phương tiện tu từ có năm chức năng là: chức năng thông báo, chức năng giải trí, chức năng thuyết phục, chức năng bày tỏ ý kiến cá nhân và chức năng giảng dạy (xem thêm Burke, 2014: 19; McGuigan và cộng sự, 2007: 3).

Biện pháp tu từ (BPTT) là "cách phối hợp sử dụng trong hoạt động lời nói các phương tiện ngôn ngữ, không kể là trung hòa hay hay tu từ trong một ngữ cảnh rộng để tạo ra hiệu quả tu từ (tức tác dụng gây ấn tượng về hình ảnh, cảm xúc, thái độ, hoàn cảnh" (Đinh Trọng Lạc, 1994: 142).

\subsubsection{Phân loại phuoong tiện tu tù và biện pháp tu tì̀}

Trên cơ sở lý thuyết, tùy vào phương tiện ngôn ngữ được kết hợp cũng như cấp độ ngôn ngữ của các yếu tố ngôn ngữ có ý nghĩa, các phương tiện tu từ hoặc biện pháp tu từ được phân loại thành các nhóm chính bao gồm: PTTT từ vựng (từ thi ca, từ mượn, từ nghề nghiệp...), PTTT - ngữ nghĩa (ẩn dụ, hoán dụ, nói mỉa, nói quá, chơi chữ, nghịch hợp), PTTT văn bản (rút gọn, mở rộng, đảo trật tự), BPTT cú pháp (sóng đôi, lặp, câu hỏi tu từ), BPTT ngữ âm (điệp âm đầu, gieo vần) (Đinh Trọng Lạc, 1994: 11). Trong phạm vi bài viết, tác giả tập trung nghiên cứu một số phương tiện tu từ như ẩn dụ, hoán dụ, và nghiên cứu một số biện pháp tu từ như biện pháp sóng đôi, câu hỏi tu từ được sử dụng trong kiến tạo bản tin.

Về phương diện phương tiện tu từ ngữ nghĩa, Đinh Trọng Lạc (1994: 52-66) định nghĩa và đưa ra các ví dụ về phương tiện tu từ ẩn dụ và hoán dụ như sau:

Ẩn dụ là "sụ định danh thứ hai mang $y$ ' nghĩa hình tượng, dựa trên sụ tương đồng (có tính chất hiện thực hoạc tvoơng tvợng ra) giữa khách thể (hoặc hiện troọng, hoạt động, tính chất), A được định danh với khách thể (hoặc hiện tượng, hoạt động, tính chất), B có tên gọi đurợc chuyển sang dùng cho A":
(Vd.4):

Giá đành trong nguyệt trên mây.

Hoa sao, hoa khéo đọa đày bấy hoa.

(Truyện Kiều)

Hoa (B) mang ý nghĩa ẩn dụ, chỉ người phụ nữ có nhan sắc $(\mathrm{A})$

Căn cứ vào từ loại và vào chức năng, vào đặc điểm ngữ nghĩa của từ ẩn dụ, ẩn dụ được chia làm các loại khác nhau: ẩn dụ định danh, ẩn dụ nhận thức và ẩn dụ hình tượng, ẩn dụ bổ sung, ẩn dụ tượng trưng, ẩn dụ cải danh, nhân hóa, vật hóa, phúng dụ và hình dung ngữ.

Hoán dụ là "sụ dịnh danh thư hai dưa trên mối liên hệ hiện thực giữa khách thể được định danh với khách thể có tên gọi được chuyển sang dùng cho khách thể được định danh":

(Vd.5):

Bàn tay ta làm nên tất cả

Có sức người sỏi đá cũng thành cơm

(Hoàng Trung Thông)

Bàn tay (công cụ kỳ diệu của lao động) làm liên tưởng đến sức sáng tạo phi thường của sức lao động.

Hoán dụ được chia làm hoán dụ cải dung, uyển ngữ, nhã ngữ, tượng trưng, dẫn ngữ và tập kiều.

Về phương diện biện pháp tu từ, Đinh Trọng Lạc (1994: 184-197) định nghĩa và đưa ra các ví dụ về biện pháp tu từ sóng đôi, câu hỏi tu từ như sau:

Sóng đôi là "biện pháp tu tù cú pháp dựa trên sự cấu tạo giống nhau giũua hai nhiều câu hoặc hai hay nhiều bộ phận của câu”:

(Vd.6):

Vì lợi ích mười năm phải trồng cây

Vì lợi ích trăm năm phải trồng người

(Hồ Chí Minh)

Sóng đôi nguyên vẹn được trình bày dưới dạng các dãy trực tiếp của các cấu trúc, đồng nhất trong giới hạn của một ngữ cảnh nào đó. 
Câu hỏi tu từ là "câu về hình thức, là câu hỏi mà về thực chất là câu khẳng định hoặc phủ định có cảm xúc. Nó có dạng không đòi hỏi câu trả lời mà chỉ nhằm tăng cuờng tính diễn cảm của phát ngôn":

(Vd.7):

Nhớ ai, ai nhớ, bây giờ nhớ ai? (Ca dao)

Câu hỏi tu từ trên nhằm biểu lộ tâm tư, tình cảm và cảm xúc của người nói.

Những định nghĩa và ví dụ về phương tiện tu từ và biện pháp tu từ được sử dụng để khảo sát trong phần nội dung nghiên cứu của bài viết này.

\subsection{Tổng quan các nghiên cứu về tiêu đề}

Từ bình diện của báo chí, qua việc khảo sát một số đề tài luận văn của học viên và bài giảng dành cho sinh viên chuyên ngành báo chí của Vũ Quang Hào (2004), tác giả Trần Thị Thanh Thảo (2009: 2-3) nhận định các nhà nghiên cứu chưa xuất phát từ bản chất nội tại của ngôn ngữ cũng như chưa làm nổi bật được tính chất, đặc điểm ngôn ngữ của báo chí. Từ đó tác giả lập ra một bảng danh sách, phân loại tiêu đề báo chí thể loại bản tin, đồng thời xác định một số đặc điểm ngôn ngữ của tiêu đề bản tin về mặt hình thức, nội dung, ngữ dụng với một số kiểu, loại tiêu đề bản tin được mô hình hoá giúp cho độc giả nói chung tiếp cận với ngôn ngữ báo chí dễ dàng hơn và những người làm công tác báo chí nói riêng có thể ứng dụng những đặc điểm của tiêu đề bản tin vào hoạt động kiến tạo tin tức báo chí của mình.

Từ bình diện của ngôn ngữ học, tác giả thấy có một số nghiên cứu về tiêu đề báo chí tuy nhiên các nghiên cứu này chỉ dừng lại ở một vài khía cạnh nào đó và phần lớn đều so sánh với tiêu đề báo chí nước ngoài hoặc so sánh tiêu đề các báo tiếng Việt, Anh, Nga, Ba Tư như một số khảo cứu dưới đây:

Tác giả Nguyễn Thị Thanh Hương (2017) khảo sát đặc điểm ngôn ngữ của các tiêu đề trong báo chí trong mối liên hệ với lời dẫn trong báo điện tử tiếng Anh qua đó phát hiện tính phổ quát, tính đặc thù trong phong cách của các báo.
Tác giả nhận thấy tuy có sự khác nhau về mức độ phát triển chủ đề của các tiêu đề báo, nhưng một loạt phương thức từ vựng và cú pháp xuất hiện trong một lời dẫn nhằm liên kết duy trì và phát triển chủ đề tạo nên mối liên hệ khăng khít không tách rời giữa tiêu đề và lời dẫn.

Nghiên cứu các tiêu đề trên báo chí Nga, tác giả Vũ Thị Chín (2007) cho rằng việc sử dụng từ trái nghĩa là một trong những thủ pháp yêu thích và được sử dụng rộng rãi trong các tiêu đề trên báo chí Nga. Tác giả Nguyễn Thị Vân Đông (2015) lại nghiên cứu so sánh những đặc trưng ngôn ngữ của tiêu đề báo chí tiếng Anh và tiếng Việt trên bình diện nghĩa học với các phương tiện tu từ phổ biến như ẩn dụ và hoán dụ hoặc các biện pháp ngữ nghĩa như chơi chữ, uyển ngữ, châm biếm và nói mỉa nhằm tạo thêm những nét nghĩa mới và nâng cao giá trị biểu cảm cho tiêu đề báo cũng như làm phong phú thêm cho ngôn ngữ báo chí.

Tác giả Trần Huy Khánh (2010) nghiên cứu các phương tiện tu từ trong tiêu đề báo chí tiếng Anh đã chỉ ra hai phương tiện tu từ nổi trội là ẩn dụ và hoán dụ được người viết sử dụng nhiều nhất trong tiêu đề báo chí, đồng thời đưa ra những khuyến nghị giúp cho việc hiểu và dịch các tiêu đề báo tiếng Anh cũng như nâng cao việc dạy và học các phương tiện tu từ.

Nhóm tác giả Bonyadi và Samuel (2011) nghiên cứu so sánh các tiêu đề xã luận (Editorials) theo hai phương diện là tiền giả định và các phương tiện tu từ trong hai tờ báo The New York Times và Tehran Times nhằm tuyên truyền cho tư tưởng mà hai tờ báo mong muốn hướng độc giả tiếp thụ. Kết quả cho thấy các tiêu đề bài báo biểu thị thái độ chủ quan của người viết đối với một chủ đề nào đó.

Qua các mục tổng quan ở trên cho thấy các bài nghiên cứu thể loại tiêu đề của các tác giả rất đa dạng về mặt chủ đề liên quan tới các vấn đề kinh tế, văn hóa, xã hội, tuy nhiên các tác giả không đi sâu nghiên cứu cụ thể vào một chủ đề, vấn đề nào đó. Việc nghiên cứu chuyên sâu ở những chủ đề khác nhau sẽ liên 
quan tới việc xem xét các đặc điểm ngôn ngữ, nghiên cứu cấu trúc và phương tiện ngôn ngữ khác nhau để kiến tạo nên tiêu đề báo chí.

Về mặt ngôn ngữ, các tác giả mới chỉ dừng lại ở việc nghiên cứu một vài khía cạnh của ngôn ngữ mà chưa đưa ra được cái nhìn tổng thể các phương tiện ngôn ngữ hoặc chưa đưa ra được lý do tại sao bài nghiên cứu được phân tích ở một số phương tiện ngôn ngữ nào đó.

Nghiên cứu tiêu đề có thể được xem xét, khảo sát từ nhiều bình diện khác nhau của báo chí và ngôn ngữ học. Trong bài viết này, tác giả tiếp cận tiêu đề trên bình diện ngôn ngữ học, cụ thể: nghiên cứu các đặc điểm, cấu trúc, các phương tiện và biện pháp tu từ được người viết sử dụng trong các tiêu đề bản tin về cuộc xung đột ở dải Gaza năm 2014 như một trường hợp nghiên cứu.

\section{Nội dung nghiên cứu}

\subsection{Mục đích nghiên cưu}

Bài viết khảo sát các đặc điểm, phân loại tiêu đề bản tin nhằm tìm hiểu xu hướng lựa chọn của người viết khi kiến tạo các tiêu đề bản tin; đồng thời tác giả cũng nghiên cứu các phương tiện và biện pháp tu từ nổi trội được sử dụng như thế nào trong các tiêu đề bản tin về cuộc xung đột ở dải Gaza năm 2014 nhằm giúp độc giả, người học, người dạy lĩnh hội được các nội dung, đặc điểm ngôn ngữ thể loại tiêu đề bản tin về chiến tranh xung đột.

\subsection{Câu hỏi nghiên cúu}

Bài viết được tiến hành với mục đích tìm ra câu trả lời cho các câu hỏi nghiên cứu (CHNC) dưới đây:

(CHNC.1): Những đặc điểm ngôn ngữ nổi trội trong các tiêu đề bản tin về cuộc xung đột ở dải Gaza năm 2014 được sử dụng như thế nào trong thời báo The New York Times?

(CHNC.2): Những cấu trúc trong các tiêu đề bản tin về cuộc xung đột ở dải Gaza năm 2014 được sử dụng như thế nào trong thời báo
The New York Times?

(CHNC.3): Những phương tiện tu từ nổi trội được các nhà báo sử dụng như thế nào trong việc kiến tạo các tiêu đề bản tin về cuộc xung đột này?

\subsection{Phwơng pháp nghiên cúu}

Phương pháp nghiên cứu được áp dụng là nghiên cứu khảo sát. Công cụ khảo sát là ba bảng mã thiết lập chi tiết đặc điểm, cấu trúc của tiêu đề bản tin và các phương tiện, biện pháp tu từ được dùng để kiến tạo các tiêu đề bản tin. Nội dung đặc điểm tiêu đề bản tin tập trung vào các hiện tượng ngôn ngữ bề mặt. Nội dung của cấu trúc tập trung vào cấu trúc tiêu đề vị từ, cấu trúc tiêu đề phi vị từ và các tiểu mục của các cấu trúc này. Nội dung của phương tiện, biện pháp tu từ tập trung khảo sát các phương tiện tu từ ngữ nghĩa từ vựng như: ẩn dụ, hoán dụ, hoặc các biện pháp tu từ như câu hỏi tu từ, sóng đôi được dùng như thế nào trong các trường hợp cụ thể.

\subsection{Phương pháp thu thập dũ liệu}

Dữ liệu được thu thập dựa trên ngữ liệu (a corpus data) của 50 tiêu đề bản tin (news headline) của thời báo The NYT đưa tin về cuộc xung đột ở dải Gaza giữa Israel và Palestine kéo dài 50 ngày từ ngày 8 tháng 7 đến ngày 26 tháng 8 năm 2014. Dũ liệu là tiêu đề trong các bản tin của thời báo The NYT được tìm và chiết suất trên trang lưu trữ cơ sở dữ liệu điện tử của ProQuest (Proquest là bộ cơ sở dữ liệu lớn bao gồm 25 cơ sở dữ liệu đa ngành tại địa chỉ https:// www.proquest.com) bằng các từ khóa: "Gaza AND Palestin* AND Israel* AND Hamas", thể loại bản tin: "NEWS" và ngày tháng cần tìm là: "DATE ranged from 8th July 2014 to 26th August 2014". Lý do cho việc chọn một khoảng thời gian và chủ đề cụ thể như trên nhằm giúp người nghiên cứu dễ dàng nhận diện các chủ đề hẹp trong cùng một chủ đề về xung đột cũng như quản lý 
được quá trình phân tích dữ liệu của mình tốt hơn (Carvalho, 2008: 173).

Thời báo The NYT được chọn để nghiên cứu vì đây là một tờ báo lề trái được mệnh danh là "tờ báo lớn và danh tiếng" (newspaper of record) với 125 lần đạt giải báo chí danh giá Pulitzer của Mỹ kể từ năm 1918. Thời báo The NYT ra số đầu tiên năm 1851 và là tờ báo có lượng phát hành lớn thứ hai (1.865.318 bản) sau tờ The Wall Street Journal tại Mỹ (theo bảng xếp hạng năm 2013 của Hãng kiểm toán báo chí phi lợi nhuận Bắc Mỹ - Alliance for Audited Media).

\subsection{Phương pháp phân tích dĩu liệu}

Nghiên cứu được tiến hành kết hợp giữa phương pháp phân tích dữ liệu định lượng và định tính, dựa trên ngữ liệu của 50 tiêu đề bản tin của thời báo The NYT và thủ pháp phân tích nội dung (content analysis) để miêu tả đặc điểm ngôn ngữ, phân loại tiêu đề bản tin theo hai cấu trúc chính là cấu trúc tiêu đề vị từ và cấu trúc tiêu đề phi vị từ, đồng thời khảo sát phương tiện và biện pháp tu từ nổi trội được người viết sử dụng như thế nào trong các tiêu đề bản tin về cuộc xung đột, bài viết phân tích kết quả tập trung vào những phân tích, nhận định khái quát các đặc điểm, cấu trúc, phương tiện và biện pháp tu từ được người viết sử dụng trong quá trình kiến tạo các tiêu đề bản tin về cuộc xung đột.

\section{Kết quả và thảo luận}

\subsection{Tổng quan về đặc điểm và phân loại tiêu đề bản tin}

\subsection{1. Đặc điểm tiêu đề bản tin}

Dựa vào Bảng 1 về đặc điểm ngôn ngữ tiêu đề ở trên, tác giả tổng hợp thống kê tần suất xuất hiện của các đặc điểm ngôn ngữ trong các tiêu đề bản tin như Bảng 2 dưới đây. Một số đặc điểm khác biệt được đề cập kèm các ví dụ dưới đây để làm rõ thêm vấn đề đang được bàn luận.

Một đặc điểm chung của các tiêu đề bản tin trên thời báo The NYT là tất cả các chữ cái đầu của từ mang nội dung thông tin (lexical or content words) được viết hoa, các chữ cái đầu của từ có chức năng ngữ pháp (functional or grammatical words) như $a$, an, the, and, for, as, to, on, in, of, if, at, không được viết hoa:

(Vd.8): Blasts Kill 16 Seeking Haven at Gaza School (Các vụ nổ giết chết 16 người đang tìm nơi trú ẩn tại một ngôi trường ở dải Gaza)

Tác giả khảo sát 10 báo chủ đạo (mainstreams) của Anh và Mỹ thì hiện tượng viết hoa các từ mang thông tin chỉ có ở hai tờ báo của Mỹ là The NYT và The Wall Street Journal, điều này có thể chủ trương muốn nhấn mạnh tất cả các thông tin quan trọng mà toà báo muốn truyền tải tới độc giả thông qua các tiêu đề bản tin. Tuy nhiên vẫn có 3 trường hợp các chữ cái đầu của từ có chức năng ngữ pháp (functional or grammatical words) như from và into được viết hoa:

(Vd.9): Artists' Work Rises From the Destruction of the Israel-Gaza Conflict (Tác phẩm nghệ thuật của các họa sĩ lấy cảm hứng từ sự hủy diệt trong cuộc xung đột của Israel tại Gaza)

Từ "From" được viết hoa chữ cái đầu như muốn nhấn mạnh nguồn gốc, xuất phát điểm của cảm hứng nghệ thuật từ sự hủy diệt của bom đạn với những ngôi nhà bị phá hủy, những hố bom và những thi thể đã được khâm liệm đều là những biểu tượng và những câu chuyện để tạo nên các tác phẩm nghệ thuật mà chỉ "các nghệ sĩ mới có thể nhìn thấy còn người thường thì không" (Artists may see things others can't see).

(Vd.10): Peering Into Darkness Beneath the Israel-Gaza Border (Binh lính Israel săn lùng và phá hủy các đường hầm trong cảnh tối tăm ở biên giới Israel và Gaza)

Từ "Into" được viết hoa chữ cái đầu như muốn nhấn mạnh đích muốn hướng tới của binh lính Israel là việc săn lùng và phá hủy các đường hầm do Hamas xây dựng để ẩn náu, cất giấu vũ khí đạn dược và xâm nhập, tấn công Israel. 
Tất cả các tiêu đề bản tin đều tuân thủ đặc điểm chung của ngôn ngữ tiêu đề là nêu tình huống, chủ đề mà bài báo sẽ đề cập trong phần nội dung của bài báo. Tuy nhiên có một tiêu đề gây khó hiểu cho độc giả như trường hợp dưới đây:

(Vd.11): Missile Strike Near U.N. School in Gaza Kills 10 (Cuộc không kích gần một ngôi trường của Liên Hiệp Quốc giết chết 10 người)

Khi đọc tiêu đề này, độc giả sẽ rất khó xác định được những người bị giết do cuộc không kích là ai nếu không đọc phần nội dung của bài báo? Người Israel hay người Palestine bị giết?

Về mặt độ dài, tiêu đề bản tin dài nhất bao gồm 14 từ (Vd.12) và tiêu đề bản tin ngắn nhất bao gồm 5 từ (Vd.13) phù hợp về giới hạn số từ như Bảng 1 đã đề cập mà vẫn đảm bảo việc truyền tải thông tin tới độc giả:

(Vd.12): Egypt Presents Proposal to Israel and Hamas for a Cease-Fire in Air Attacks.

(Vd.13): Israeli Procedure Reignites Old Debate.

Những từ mang thông tin được sử dụng nhiều hơn từ hành chức năng ngữ pháp trong tiêu đề bản tin nhằm cung cấp nhiều thông tin nhất có thể trong khuôn khổ có hạn của trang báo và tạo sức hấp dẫn cho độc giả. Trong các ví dụ trên đều có hiện tượng giản lược mạo từ, trợ động từ “to be"..., tuy vậy độc giả vẫn hiểu được tiêu đề bản tin muốn nói/đề cập về vấn đề gì. Dù không đúng về mặt ngữ pháp, việc giản lược này giúp người viết tiết kiệm, tối ưu hóa không gian cho những từ quan trọng hơn và đây cũng là xu thế tất yếu trong thời đại công nghệ 4.0 khi các tòa báo chuyển tải nội dung bài báo lên các phiên bản điện tử (online newspaper versions) và chạy các dòng tiêu đề bản tin trên các trình duyệt ứng dụng hoặc quảng bá tiêu đề bản tin trên các trang mạng xã hội facebook, twitter của độc giả.

Ví dụ 12 được viết ở dạng đầy đủ là:

(Vd.14): Egypt Presents a Proposal to Israel and Hamas for a Cease-Fire in Air Attacks

Ví dụ 13 được viết ở dạng đầy đủ là:

(Vd.15): An Israeli Procedure Reignites an Old Debate

Hiện tượng sử dụng động từ ở dạng phân từ quá khứ thay cho bị động xuất hiện duy nhất một trường hợp trong tiêu đề bản tin được khảo sát:

(Vd.16): Boys Drawn to Gaza Beach, and into Center of Mideast Strife (Xác những cậu bé thiệt mạng bên bờ biển là tâm điểm của tranh cãi ở Trung Đông)

Câu viết đầy đủ là "Boys were Drawn to Gaza Beach, and into Center of Mideast Strife".

Bảng 2. Tần suất xuất hiện của các đặc điểm ngôn ngữ trong các tiêu đề bản tin

\begin{tabular}{|c|c|c|}
\hline TT & Đặc điểm ngôn ngữ tiêu đề & $\begin{array}{c}\text { Tần suất xuất hiện trong các } \\
\text { tiêu đề bản tin }\end{array}$ \\
\hline 1 & Nêu tình huống, chủ đề & 49 \\
\hline 2 & Giới hạn về số lượng từ (không quá 45 ký tự) & 50 \\
\hline 3 & Câu có cấu trúc đơn giản nhưng ở dạng đầy đủ (S-V) & 43 \\
\hline 4 & Cho phép giản lược mạo từ, trợ động từ "to be" và giới từ & 30 \\
\hline 5 & Dùng dạng phân từ quá khứ thay cho bị động & 1 \\
\hline 6 & Dùng dạng hiện tại đơn thay cho tiếp diễn và hoàn thành & 27 \\
\hline 7 & Dạng nguyên thể "to-V" thể hiện nghĩa tương lai & 3 \\
\hline 8 & Dùng câu hạt nhân (S-V-O) & 17 \\
\hline 9 & Chuỗi các danh từ & 2 \\
\hline 10 & Dùng dấu ':' phân cách chủ ngữ và phần còn lại của tiêu đề & 0 \\
\hline 11 & Từ ngắn có khả năng biểu cảm & 0 \\
\hline
\end{tabular}




\subsubsection{Phân loại tiêu đề bản tin}

Tiêu đề bản tin quyết định tới sự thành công của một bài viết, nó quyết định tới việc độc giả có muốn đọc tiếp phần còn lại của bài báo hay không. Bảng 3 dưới đây tổng hợp phân loại cấu trúc tiêu đề bản tin của thời báo The NYT. Số liệu trong bảng cho thấy tỉ lệ chênh lệch rất lớn về cấu trúc giữa các tiêu đề bản tin là những cú có vị từ với 46 tiêu đề (tương đương với 92\%) so sánh với các tiêu đề bản tin là những cú không chứa vị từ với chỉ 4 tiêu đề (tương đương với $8 \%$ ). Việc người viết sử dụng nhiều cấu trúc tiêu đề bản tin là những cú có vị từ biến ngôi giúp độc giả tiếp cận nhanh chóng các thông tin chủ đề của bài báo, đồng thời độc giả không phải dừng lại ở ngay tiêu đề để suy luận hay phỏng đoán những nội dung sẽ được nói đến trong phần nội dung của bài báo như những cú không chứa vị từ. Điều này thể hiện rõ tầm quan trọng của tiêu đề bản tin với mức độ thông tin càng quan trọng và có tính khái quát cao được đưa lên phần tiêu đề, qua đó cho phép người viết mở rộng nghĩa nhằm phát triển chủ đề của tiêu đề bản tin.

Ngoài ra, tiêu đề bản tin ở những cú không chứa vị từ đều có thành phần phụ ngữ bổ sung thêm thông tin cho danh từ chính trong cú. Xin xem một số ví dụ dưới đây với từ/cụm từ in đậm nhằm minh họa cho vấn đề đang được đề cập (chi tiết xin xem phần Phụ lục).

Bảng 3. Phân loại tiêu đề bản tin của thời báo The New York Times

\begin{tabular}{|c|c|c|c|c|c|c|c|c|c|c|c|}
\hline \multicolumn{4}{|c|}{ Cú có vị từ } & \multicolumn{6}{c|}{ Cú không chứa vị từ } \\
\hline \multicolumn{2}{|c|}{ Biến ngôi } & \multicolumn{2}{|c|}{$\begin{array}{c}\text { Không biến } \\
\text { ngôi }\end{array}$} & $\begin{array}{c}\text { Tiền phụ } \\
\text { ngữ }\end{array}$ & \multicolumn{2}{|c|}{ Hậu phụ ngữ } & $\begin{array}{c}\text { Tiền và hậu phụ } \\
\text { ngứ }\end{array}$ & \multicolumn{2}{c|}{ Phi phụ ngũ̃ } \\
\hline $\mathrm{N}$ & $\%$ & $\mathrm{~N}$ & $\%$ & $\mathrm{~N}$ & $\%$ & $\mathrm{~N}$ & $\%$ & $\mathrm{~N}$ & $\%$ & $\mathrm{~N}$ & $\%$ \\
\hline 43 & $86 \%$ & 3 & $6 \%$ & 2 & $4 \%$ & 0 & $0 \%$ & 2 & $4 \%$ & 0 & $0 \%$ \\
\hline
\end{tabular}

Ví dụ về các cú có vị từ biến ngôi:

(Vd.17): Israel and Hamas Trade Attacks as Tension Rises (Israel và Hamas trả đũa lẫn nhau bằng các cuộc tấn công giữa lúc căng thẳng leo thang)

(Vd. 18): Israeli Leader Vows to Intensify Gaza Attacks on Hamas (Lãnh đạo Israel thề sẽ tăng cường tấn công Hamas ở Gaza)

Ví dụ về các cú có vị từ không biến ngôi:

(Vd.19): Boys Drawn to Gaza Beach, and into Center of Mideast Strife (Xác những cậu bé thiệt mạng bên bờ biển là tâm điểm của tranh cãi ở Trung Đông)

Người viết sử dụng cấu trúc "someone to be drawn to something” để chỉ ai đó bị cuốn hút/ thu hút bởi điều gì đó. Từ "drawn" trong trường hợp này vừa có nghĩa là "cuốn hút" trong "Boys Drawn to Gaza Beach" (Những cậu bé bị cuốn hút bởi bờ biển Gaza) vừa có nghĩa "bị lôi kéo vào" trong đoạn tiếp theo "and into Center of Mideast Strife", tiêu đề bản tin được hiểu theo nghĩa đen là những đứa trẻ đang chơi đùa trên bờ biển Gaza thì bị thiệt mạng bởi bom đạn của Israel, sự việc này là tâm điểm kéo theo tranh cãi ở Trung Đông. Trẻ em luôn được che chở và bảo vệ, nhưng khi xung đột xảy ra trẻ em luôn bị tổn thương bởi những bom rơi đạn lạc. Hình ảnh ảnh trẻ em thiệt mạng trong chiến tranh như một biểu tượng cho nỗi đau mà các em phải hứng chịu và đối mặt hàng ngày, điều này khiến cho độc giả bị sốc bởi sự ám ảnh và đau thương tột cùng.

(Vd.20): In a Palestinian Town, Growing Weary of a War and Hoping for Change (Ở một thị trấn của người Palestine, người dân đang kiệt sức vì chiến tranh và vẫn đang hy vọng sự đổi thay) 
Ví dụ về các cú không chứa vị từ là tiền phụ ngữ:

(Vd.21): For Gazans, an Anxious and Somber Ramadan (Tháng nhịn ăn Ramadan đầy âu lo và sợ hãi đối với người dân Gaza)

Ví dụ về các cú không có vị từ biến ngôi là tiền và hậu phụ ngữ:

(Vd.22): Trouble Underfoot on Israeli Kibbutz Near the Border (Tình trạng bất an tiềm ẩn dưới lòng đất ở làng cộng đồng gần biên giới đe dọa người Israel)

(Vd.23): Former New York Judge on U.N. Gaza Panel (Cựu thẩm phán của bang New York là thành viên của ban hội thẩm Liên Hiệp Quốc về Gaza)
4.2. Các phương tiện và biện pháp tu tù được sủ dụng trong tiêu đề bản tin

Như đã bàn luận ở các phần 2.3.1 về định nghĩa và phần 2.3 .2 về phân loại phương tiện và biện pháp tu từ cùng với việc khảo sát sơ bộ các tiêu đề bản tin, tác giả nhận thấy có $6 / 50$ tiêu đề bản tin được người viết sử dụng các phương tiện và biện pháp tu từ (xin xem chi tiết tại Bảng 4). Bài viết này tập trung mô tả, phân tích và đưa ra các nhận xét việc sử dụng phương tiện và biện pháp tu từ nổi trội như ẩn dụ, hoán dụ, biện pháp sóng đôi, câu hỏi tu từ được sử dụng như thế nào trong việc kiến tạo tiêu đề bản tin.

Bảng 4. Bảng phân loại tiêu đề bản tin theo phương tiện và biện pháp tu từ

\begin{tabular}{|c|c|c|}
\hline \multicolumn{2}{|c|}{ Phương tiện ngôn ngữ } & Các tiêu đề bản tin \\
\hline \multirow{2}{*}{ Phương tiện tu từ } & Ần dụ & $\begin{array}{r}\text { Civilians as Human Shields? Gaza War Intensifies Debate } \\
\text { Tunnels Lead Right to Heart of Israeli Fear } \\
\text { Hamas Gambled on War as Woes Grew in Gaza }\end{array}$ \\
\cline { 2 - 3 } & Hoán dụ & In Torn Gaza, if Roof Stands, It's Now Home \\
\hline \multirow{2}{*}{ Biện pháp tu từ } & Câu hỏi tu từ & Civilians as Human Shields? Gaza War Intensifies Debate \\
\cline { 2 - 3 } & Sóng đôi & Israel Exits Gaza; Truce Takes Hold \\
\hline
\end{tabular}

\subsubsection{Các phương tiện tu tù̀}

\subsubsection{An $d u$}

Theo kết quả khảo sát thì ẩn dụ là phương tiện được sử dụng nhiều nhất với 3 lần trong số các phương tiện tu từ xuất hiện. Ví dụ:

(Vd.24): Civilians as Human Shields? Gaza War Intensifies Debate (Dân thường có phải là những lá chắn sống? Cuộc chiến ở dải Gaza dấy lên những tranh cãi)

Người viết đã sử dụng phương tiện tu từ ẩn dụ để nhắc lại cáo buộc của thủ tướng Israel Netanyaho (khi ông thảo luận với người đồng cấp Canada) đối với chính quyền Hamas ở dải Gaza đã dùng dân thường Palestine như những "lá chắn sống" trước các cuộc không kích của Israel. Hình ảnh "lá chắn" thường được biết đến như một nơi ẩn náu, che chở an toàn cho con người trong các thảm họa hoặc trong các cuộc bắn phá, oanh kích bằng bom đạn của các bên trong chiến tranh, xung đột. Trong trường hợp này dân thường được người viết (gián tiếp dùng lại cáo buộc của thủ tướng Israel) ví như những "lá chắn sống" gợi sự thương cảm của độc giả đối với những nạn nhân của chiến tranh. Tiêu đề bản tin trong ví dụ 12 này được đăng trên trang nhất của thời báo The NYT ngày 23 tháng 7 năm 2014, tuy nhiên tiêu đề bản tin trong phiên bản điện tử của báo này đã được đính chính vào ngày 8 tháng 10 năm 2014 thành "Israel says that Hamas Uses Civilian Shields, Reviving Dabate" (Israel cáo buộc Hamas dùng dân thường của mình làm lá chắn sống dấy lên những tranh cãi) cùng với việc giải thích là ở phiên bản báo in trước đó đã thông tin không 
chính xác về "lá chắn sống" mặc dù thời báo The NYT cho rằng không có quy định bắt buộc nào về việc đề cập thông tin như vậy bằng việc viện dẫn định nghĩa "lá chắn sống" của luật quốc tế là việc quân đội sử dụng có chủ đích dân thường làm lá chắn sống để ngăn chặn các cuộc tấn công từ kẻ thù.

(Vd.25): Tunnels Lead Right to Heart of Israeli Fear (Các đường hầm dẫn thẳng tới trái tim sợ hãi của người Israel)

Trong ví dụ này người viết sử dụng biện pháp tu từ ẩn dụ với nghĩa đen là "trái tim sợ hãi của người Israel", còn hiểu theo nghĩa tu từ có thể là: Các đường hầm là tâm điểm sợ hãi của người Israel. Việc bố trí hệ thống tên lửa đánh chặn "Vòm sắt" (Iron Dome) với hiệu suất 90-95\% của Israel đã buộc Hamas phải thay đổi chiến thuật tấn công Israel (xem thêm Đặng Hoàng Xa, 2014). Hamas sử dụng các đường hầm ở dải Gaza xuyên sâu vào lãnh thổ của Israel vừa làm nơi ẩn nấp, tránh trú bom hoặc trao đổi giao thương, cất giấu vũ khí đạn dược và cũng là nơi Hamas sử dụng làm các trạm căn cứ để bắn các tên lửa về phía Israel hoặc xâm nhập (infiltrate) vào lãnh thổ Israel để tấn công binh lính Israel rồi nhanh chóng biến mất xuống lòng đất. Việc dò tìm và phá hủy các đường hầm này là không hề dễ dàng đối với quân đội Israel cho dù họ có các phương tiện hiện đại hỗ trợ, điều này làm gia tăng tình trạng bất an của Israel mỗi khi xung đột giữa Israel và Palestine xảy ra.

(Vd.26): Hamas Gambled on War as Woes Grew in Gaza (Hamas đánh bạc với chiến tranh khi thương vong tăng lên ở dải Gaza)

Việc đánh bạc thường được biết đến là có bên thắng và bên thua/ được mất (option zero) trong một cuộc chơi có giải mà người chơi phải đầu tư bằng tiền của chính mình, tuy nhiên trong trường hợp này người viết muốn ám chỉ những chiến thuật quân sự mà Hamas đang dùng (trong khi Hamas bị bao vây tất cả các mặt chính trị, kinh tế, ngoại giao) để chống lại sự tấn công của Israel đôi khi phải đánh đổi bằng sự mất mát, thương vong về người cả dân thường và binh lính, tổn hao lực lượng, vũ khí, khí tài, sự ủng hộ của người dân và của cộng đồng quốc tế.

Việc sử dụng phương tiện tu từ ẩn dụ trong các trường hợp trên nhằm làm nổi bật nội dung tiêu đề bản tin gây sự tò mò, hấp dẫn thu hút độc giả.

\subsubsection{Hoán $d u$}

Hoán dụ là một biện pháp để người viết tạo cách nói, cách viết mới. Đứng trước những từ ngữ được tạo từ hoán dụ, độc giả đôi khi gặp khó khăn trong việc nhận diện được rõ ràng từ ngữ đó là hoán dụ hay là ẩn dụ vì có rất nhiều trường hợp hoán dụ giáp ranh với ẩn dụ.

(Vd.27): In Torn Gaza, if Roof Stands, it's now Home (Ở dải Gaza đổ nát, khi một mái nhà còn trụ vững, thì đó là nhà)

Động từ "stand" có nghĩa là trụ vững, đứng vững, trong trường hợp này người viết miêu tả tình trạng vật lý của mái nhà đứng vững trước bom đạn của Israel bắn vào và cũng là nơi trú ngụ của người dân dải Gaza qua đó người viết gián tiếp nói lên ý chí kiên cường của người dân Palestine ở dải Gaza trong mọi hoàn cảnh.

\subsubsection{Các biện pháp tu tù}

\subsubsection{Câu hỏi tu tì̀}

Câu hỏi tu từ được người viết sử dụng nhằm tạo ra hiệu ứng nhấn mạnh tác động sâu sắc đến độc giả:

(Vd.28): Civilians as Human Shields? Gaza War Intensifies Debate (Dân thường có phải là những lá chắn sống? Cuộc chiến ở dải Gaza dấy lên những tranh cãi)

Người viết nhấn mạnh hình ảnh "lá chắn sống" (human shields) như một thủ pháp đối lập giữa con người chống chọi với vũ khí của chiến tranh nhằm khắc họa sự tàn khốc, chết chóc thương vong mà dân thường ở dải Gaza đang phải đối mặt và gánh chịu. Dạng câu hỏi tu từ này trong tiêu đề bản tin vừa biểu thị sự hoài nghi, tranh cãi về một vấn đề đang được 
quan tâm "lá chắn sống", vừa gợi sự phán đoán, suy ngẫm và muốn tìm câu trả lời của độc giả vừa hứa hẹn sẽ có câu trả lời thỏa đáng ở phần nội dung của bản tin. Dấu hỏi còn được dùng để nhấn mạnh ý đồ của tác giả nhằm thu hút sự chú ý của độc giả muốn khám phá, tìm tòi những điều, những vấn đề đang xảy ra ở quanh mình.

\subsubsection{Sóng đô $i$}

Biện pháp tu từ sóng đôi được người viết sử dụng để nhấn mạnh điểm trọng tâm tới độc giả:

(Vd.29): Israel Exits Gaza; Truce Takes Hold (Khi Israel rút quân khỏi Gaza, thỏa thuận ngừng bắn cũng được thiết lập)

Việc tuyên bố rút quân của Israel được người viết đề cập song hành với thỏa thuận ngừng bắn 72 giờ được thực hiện như một thông điệp thuyết phục độc giả là Israel đang thực thi thỏa thuận như một sự cam kết.

Người viết sử dụng các phương tiện tu từ như ẩn dụ, hoán dụ, hoặc các biện pháp tư từ như câu hỏi tu từ, sóng đôi một cách tinh tế nâng cao hiệu quả diễn đạt, giúp tiêu đề bài báo không khô khan, độc giả có thể tiếp nhận một cách nhẹ nhàng hơn. Việc sử dụng các phương tiện tu từ trên cũng tạo ra những ý tưởng gợi mở, khiến độc giả cảm thấy những thông tin của nhà báo dễ hiểu, dễ tiếp cận về mặt nội dung và làm tăng tính sinh động hấp dẫn của báo chí từ bình diện ngôn ngữ học.

\section{Kết luận}

Nghiên cứu tiêu đề bản tin đã được đề cập trong nhiều công trình nghiên cứu từ bình diện báo chí hoặc bình diện ngôn ngữ học. Tuy nhiên, việc tiếp cận tiêu đề bản tin từ bình diện ngôn ngữ học ở các chủ đề cụ thể vẫn chưa được quan tâm, đặc biệt là từ góc độ đặc điểm, cấu trúc tiêu đề bản tin, phương tiện và biện pháp tu từ. Ở góc độ đặc điểm ngôn ngữ, các tiêu đề bản tin của thời báo The NYT sử dụng việc viết hoa các chữ cái đầu của những từ mang nội dung thông tin, giản lược các mạo từ, trợ động từ, giới từ nhằm truyền tải nội dung thông tin nhanh nhất tới độc giả, đồng thời giúp tòa báo dễ dàng đăng tải nội dung bài báo lên các phiên bản báo điện tử cũng như cập nhật các tiêu đề bản tin trên các trang mạng xã hội như facebook, twitter. Ở góc độ cấu trúc, các tiêu đề bản tin có cấu trúc cú có vị từ biến ngôi được sử dụng nhiều hơn cú không chứa vị từ nhằm khái quát hóa nội dung bản tin giúp độc giả tiếp cận nhanh chóng, chính xác các nội dung thông tin của bài báo. Ở góc độ phương tiện và biện pháp tu từ học, người viết sử dụng các phương tiện tu từ như ẩn dụ, hoán dụ, hoặc các biện pháp tư từ như câu hỏi tu từ, sóng đôi nâng cao hiệu quả diễn đạt, truyền tải thông tin, giúp độc giả có thể tiếp nhận nội dung các tiêu đề bản tin một cách nhẹ nhàng nhưng ẩn chứa nhiều thông điệp nhân văn sâu sắc. Từ đó có thể thấy người viết rất chú trọng đến hình thức đặc điểm ngôn ngữ và văn phong, phương tiện ngôn ngữ trong việc đặt tên tiêu đề bản tin cho các tác phẩm báo chí của thời báo The NYT, nhằm nâng cao chất lượng nội dung của bài báo cũng như uy tín của tờ báo.

Tiêu đề bản tin có vai trò đặc biệt quan trọng và được xem như một thông điệp đầu tiên của bài báo mà người viết muốn gửi tới độc giả. Một tiêu đề hay, hiệu quả đòi hỏi nhiều vào ý tưởng của người viết về mặt cấu trúc và nội dung. Đặc biệt, với những tiêu đề bản tin về xung đột cần sự chăm chút chuyên nghiệp của người viết bởi qua đó, nội dung của bài báo truyền tải nhiều thông điệp có ý nghĩa nhân văn sâu sắc tới độc giả, có sức lay động sự cảm thông của độc giả về số phận những con người đang hàng ngày phải hứng chịu bom đạn trong các cuộc xung đột.

Nghiên cứu này dựa trên một ngữ liệu (a corpus) nhỏ với 50 tiêu đề bản tin đại diện cho 50 ngày xung đột ở dải Gaza giữa Israel và Palestine trong thời báo The NYT năm 2014, do đó, phần khảo sát có thể chưa khái quát hết đặc điểm, cấu trúc và phương tiện, biện pháp tu từ được dùng trong việc kiến tạo tiêu đề bản tin, 
đồng thời, tiêu chí nổi trội/ không nổi trội được mô tả trong bài viết chỉ mang tính chất tương đối. Tuy vậy, tác giả mong muốn phần nào dữ liệu đáp ứng được yêu cầu miêu tả đặc điểm, phân loại cấu trúc tiêu đề bản tin và phân tích các phương tiện, biện pháp tu từ được người viết sử dụng trong việc kiến tạo các tiêu đề bản tin, qua đó đáp ứng thực tiễn khả năng tiếp cận ngôn ngữ báo chí của độc giả ở các mức độ, chức năng ngôn ngữ khác nhau. Bài báo đóng góp vào thực tiễn nâng cao công tác giảng dạy và nghiên cứu đặc điểm, cấu trúc, phương tiện ngôn ngữ được sử dụng trong các tiêu đề báo chí về các chủ đề khác nhau giúp cho người học sử dụng tốt cấu trúc, phương tiện và biện pháp tu từ trong hoạt động viết các bài luận về tiêu đề bản tin ở trường, hoạt động nhận biết lỗi và cách sửa lỗi trong cách dịch tiêu đề bản tin cũng như nhận biết các dạng tiêu đề bản tin khi tiếp cận báo chí tiếng Anh ngoài đời thực.

\section{Tài liệu tham khảo}

\section{Tiếng Việt}

Vũ Thị Chín (2007). Từ trái nghĩa trong các tiêu đề trên báo chí Nga. Ngôn ngũ, 1, 44-51.

Nguyễn Thị Vân Đông (2015). Những đặc trưng ngôn ngữ của tiêu đề báo chí tiếng Anh và tiếng Việt trên bình diện nghĩa học. Ngôn ngũ \& Đời sống, 7(237), 7-11.

Vũ Quang Hào (2004). Ngôn ngũ báo chí. Hà Nội: Nxb Đại học Quốc gia Hà Nội.

Nguyễn Thị Thanh Hương (2017). Mối liên hệ giữa tiêu đề và lời dẫn trong báo điện tử tiếng Anh. Nghiên cứu Nước ngoài, 33(5), 47-65.

Trần Huy Khánh (2010). Khảo sát các phương tiện tu từ sử dụng trong tiêu đề báo chí tiếng Anh. Tạp chí Khoa học và Công nghệ, Đại học Đà Nã̃ng, 5(40), 126-132.

Đinh Trọng Lạc (1994). 99 Phuoong tiện và Biện pháp tu tù̀ tiếng Việt. Hà Nội: Nxb Giáo dục.

Trịnh Hồng Nam (2009). Nghiên cứu cấu trúc diễn ngôn và đặc điểm ngôn ngữ bản tin công nghệ thông tin tiếng Anh. Tạp chi Khoa học Trường Đại học Hồng Đúc, 1, 79-83.

Trần Thị Thanh Thảo (2009). Đặc điểm của tiêu đề văn bản trong thể loai tin tức. Luận văn thạc sĩ. TP. Hồ Chí Minh: Trường Đại học Sư phạm thành phố Hồ Chí Minh.
Đặng Hoàng Xa (2014). Câu chuyện Do Thái: Lịch sủ thăng trầm của một dân tộc. (Tập 1). Hà Nội: Nxb Hồng Đức.

\section{Tiếng Anh}

Bednarek, M. \& Caple, H. (2012). News discourse. London: Continuum International Publishing.

Bell, A. (1991). The Language of News Media. Oxford: Blackwell.

Bonyadi, A., Samuel, M. (2013). Headlines in newspaper Editorials: A constrastive Study. SAGE Open 3(2), pp. 1-10.

Burke, M. (2014). Rhetoric and poetics: The classical heritage of stylistics. In M. Burke (ed.) The Routledge Handbook of Stylistics (pp. 11-30). London and New York: Routledge.

Carvalho, A. (2008). Media(ted) Discourse and Society: Rethinking the framework of Critical Discourse Analysis. Journalism Studies. 9(2), 161-177.

Cotter, C. (2010). News Talk: Investigating the Language of Journalism. UK: Cambridge University Press.

Galperin, I. R. (1981). Stylistics. Moscow: Higher school Publishing House.

Halliday, M. A. K. (1978). Language as a Social Semiotic: The Social Interpretation of Language and Meaning. London: Edward Arnold.

Halliday, M. A. K. (1994). An introduction to Functional Grammar, (2 ${ }^{\text {nd }}$ ed). London: Edward Arnold.

Halliday, M. A. K., \& Matthiessen, C. M. I. M. (2014). Halliday's introduction to functional grammar, $\left(4^{\text {th }}\right.$ ed). London: Routledge.

Harkrider, J. (1997). Getting started in Journalism. National Textbook company.

Mallette, M. F. (1990). Handbook for Journalists of Central and Eastern Europe. World Press Free Committee.

McGuigan, B., Grudzina, D., Moliken, P. (2007). Rhetorical Devices: A Handbook and Activities for Student Writers. Clayton (DE): Prestwick House.

Reah, D. (2002). The Language of Newspapers. London: Routledge.

Richardson, J. E. (2007). Analysing newspapers: An approach from critical discourse analysis. Houndmills: Palgrave.

United Nations Office for the Coordination of Humanitarian Affairs. (2014, December, 26). Humanitarian Bulletin Monthly Report December 2014. Retrieved on 5 March, 2015 from https:// www.ochaopt.org/content/monthly-humanitarianbulletin-december-2014.

Van Dijk, T. A. (1985). Structure of news in the Press. in van Dijk, T. A. (ed.) Discourse and Communication: New approaches to the Analysis of Mass Media Discourse and Communication (pp. 69-93). Berlin: de Gruyter. 


\title{
THE 2014 GAZA CONFLICT IN THE NEW YORK TIMES NEWS HEADLINES
}

\author{
Trinh Hong Nam \\ Faculty of Post-Graduate Studies, VNU University of Languages and International Studies, \\ Pham Van Dong, Cau Giay, Hanoi, Vietnam
}

\begin{abstract}
Language plays an important role in conveying the writers'/speakers' ideal to readers/audiences in terms of structures and potential expression usage at different linguistic functions. The article is a survey research of 50 news headlines analyzed in terms of linguistic characteristics, structures and stylistic devices that journalists/editors used in The New York Times news headlines to cover the 2014 Gaza conflict between the Israelis and Palestinians. The finding shows that the journalists tended to choose some linguistic characteristics such as capitalizing the first letter of each lexical or content word, shortening articles and auxiliary verbs. Most verbal headlines with a finite clause are used in the news headlines. Some stylistic devices as metaphor, metonymy, rhetorical questions and parallelism are also effectively used by journalists to construct the news headline coverage of the 2014 Gaza conflict. These journalists' choices also help The NYT to update the latest news headlines on online newspaper versions and to run their news headlines on social media platforms like Facebook or Twitter. The article makes contributions to practical teaching and research of news headlines with various topics in terms of linguistic characteristic, structure and stylistic device usage. This article is hoped to help learners to use these linguistic characteristics, structures and stylistic devices effectively in writing compositions and translating news headlines at school and to read and to fully understand English news headlines in general as well.
\end{abstract}

Keywords: structure, news headline, stylistic device, conflict, Israel, Palestine, Gaza 


\section{PHỤ LỤC}

\section{BẢNG PHÂN LOẠI TIÊU ĐỀ BẢN TIN THEO CẤU TRÚC}

\begin{tabular}{|c|c|c|c|}
\hline \multicolumn{2}{|c|}{ Cấu trúc } & $\begin{array}{l}\text { Tần } \\
\text { suất }\end{array}$ & Tiêu đề bản tin \\
\hline \multirow[t]{4}{*}{$\begin{array}{l}\text { Cú có } \\
\text { vị từ }\end{array}$} & \multirow[t]{2}{*}{ Biến ngôi } & $\begin{array}{l}N= \\
43\end{array}$ & 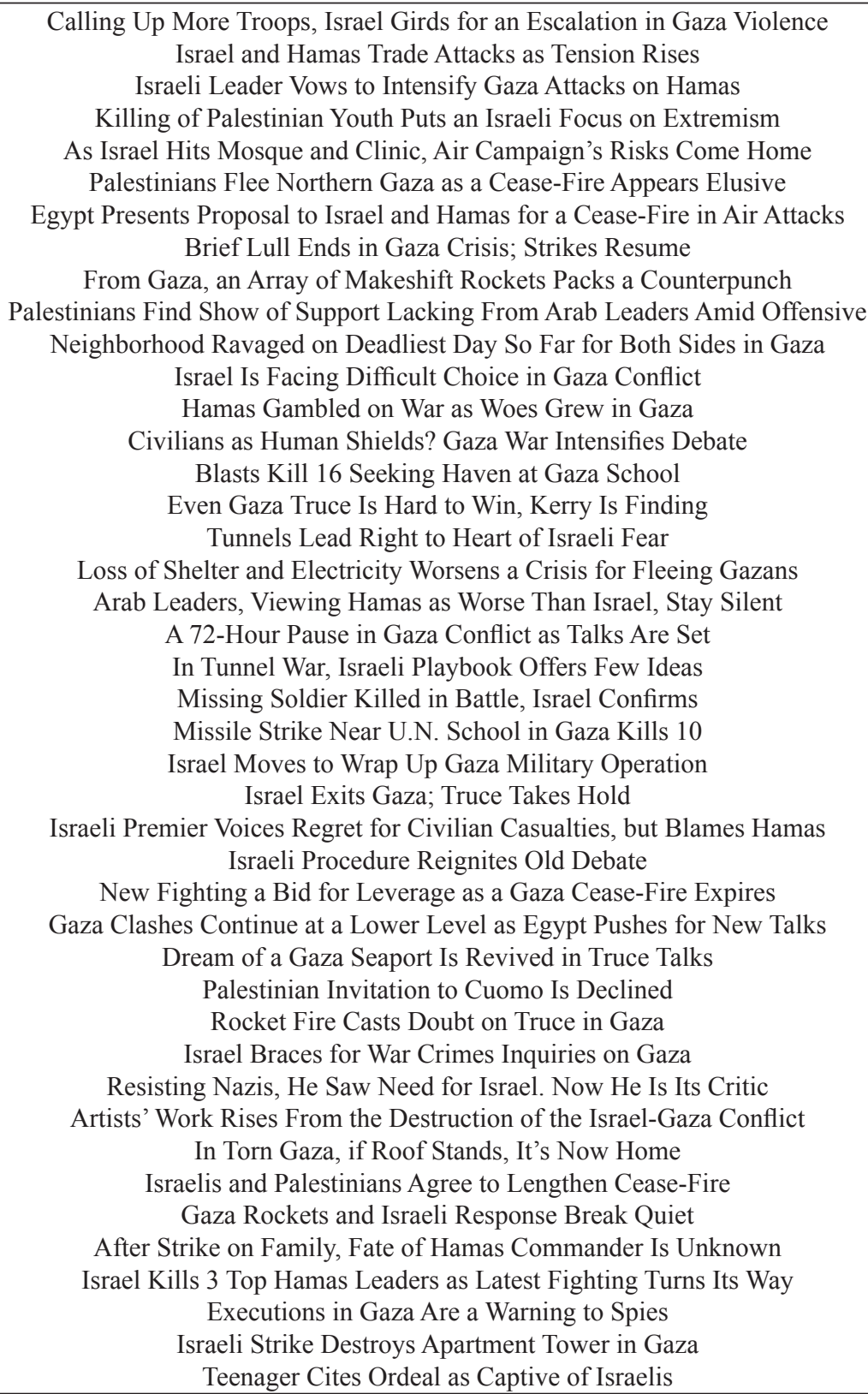 \\
\hline & & $86 \%$ & \\
\hline & \multirow[t]{2}{*}{$\begin{array}{l}\text { Không } \\
\text { biến ngôi }\end{array}$} & $\begin{array}{l}\mathrm{N} \\
=3\end{array}$ & $\begin{array}{l}\text { Boys Drawn to Gaza Beach, and Into Center of Mideast Strife } \\
\text { Peering Into Darkness Beneath the Israel-Gaza Border } \\
\text { In a Palestinian Town, Growing Weary of a War and Hoping for Change }\end{array}$ \\
\hline & & $6 \%$ & \\
\hline
\end{tabular}




\begin{tabular}{|c|c|c|c|}
\hline \multirow{8}{*}{$\begin{array}{c}\text { Cú } \\
\text { không } \\
\text { chứa vị } \\
\text { từ }\end{array}$} & \multirow{2}{*}{$\begin{array}{l}\text { Tiền phụ } \\
\text { ngữ }\end{array}$} & 2 & $\begin{array}{c}\text { For Gazans, an Anxious and Somber Ramadan } \\
\text { Amid Outcry Abroad, a Wealth of Backing in Israel for Netanyahu }\end{array}$ \\
\hline & & $4 \%$ & \\
\hline & \multirow{2}{*}{$\begin{array}{l}\text { Hậu phụ } \\
\text { ngữ }\end{array}$} & 0 & \\
\hline & & $0 \%$ & \\
\hline & \multirow{2}{*}{$\begin{array}{c}\text { Tiền và } \\
\text { hậu phụ } \\
\text { ngữ }\end{array}$} & 2 & $\begin{array}{c}\text { Trouble Underfoot on Israeli Kibbutz Near the Border } \\
\text { Former New York Judge on U.N. Gaza Panel }\end{array}$ \\
\hline & & $4 \%$ & \\
\hline & \multirow{2}{*}{$\begin{array}{l}\text { Phi phụ } \\
\text { ngữ }\end{array}$} & 0 & \\
\hline & & $0 \%$ & \\
\hline
\end{tabular}

